$\begin{array}{ll} & \text { Etnográfica } \\ \text { etnográfica } & \text { Revista do Centro em Rede de Investigação em }\end{array}$ Antropologia

vol. 21 (2) | 2017

Vol. $21(2)$

\title{
Rumo a uma fé global: história do movimento evangélico na Guiné-Bissau
}

Towards a global faith: history of the Evangelical movement in Guinea-Bissau

\section{Ambra Formenti}

\section{(2) OpenEdition}

\section{Journals}

\section{Edição electrónica}

URL: https://journals.openedition.org/etnografica/4912

DOI: 10.4000/etnografica.4912

ISSN: 2182-2891

\section{Editora}

Centro em Rede de Investigação em Antropologia

\section{Edição impressa}

Data de publição: 1 junho 2017

Paginação: 293-318

ISSN: 0873-6561

\section{Refêrencia eletrónica}

Ambra Formenti, «Rumo a uma fé global: história do movimento evangélico na Guiné-Bissau», Etnográfica [Online], vol. 21 (2) | 2017, posto online no dia 09 julho 2017, consultado o 09 fevereiro 2022. URL: http://journals.openedition.org/etnografica/4912 ; DOI: https://doi.org/10.4000/ etnografica. 4912

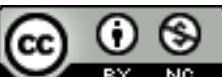

Etnográfica is licensed under a Creative Commons Attribution-NonCommercial 4.0 International License. 


\section{Rumo a uma fé global: história do movimento evangélico na Guiné-Bissau}

\section{Ambra Formenti}

Este artigo descreve a trajetória histórica da minoria evangélica na Guiné-Bissau, desde os anos 1940 até aos nossos dias. Ilustra-se como o movimento evangélico evoluiu de uma pequena comunidade socialmente marginal para uma minoria que vai crescendo e emergindo no espaço público, no contexto da crise do Estado pós-colonial na Guiné-Bissau. Para interpretar estas mudanças, propõem-se duas possíveis linhas de análise. Em primeiro lugar, mostra-se como a minoria evangélica está atualmente a praticar uma dupla estratégia, que inclui tanto um esforço para colmatar as lacunas do Estado através da ação social, como um projeto de "redenção do Estado" através da evangelização. Em segundo lugar, examina-se o crescimento do cristianismo evangélico no contexto de uma viragem geral para as religióes universais, mostrando como o sucesso das religióes globais pode estar relacionado com a capacidade de responder ao desejo de modernidade de muitos guineenses, e de ligar os crentes com o resto do mundo.

PALAVRAS-CHAVE: religião, cristianismo evangélico, Guiné-Bissau, Estado pós-colonial, modernidade, mobilidade.

Towards a global faith: history of the Evangelical movement in Guinea-Bissau - This article describes the historical trajectory of the Evangelical minority in Guinea-Bissau, from the 1940s to the present. Against the backdrop of the crisis of the post-colonial state in Guinea-Bissau, the author illustrates how the evangelical movement has evolved from a small and marginal community to a minority which is expanding and emerging in the public space. To interpret these changes, two possible lines of analysis are proposed. Firstly, the author shows how the evangelical minority is actually pursuing a double strategy of intervention in public life, which includes both an effort to repair state's shortcomings through social action, and a project of "state redemption" through evangelization. Secondly, she examines the growth of evangelical Christianity in the context of a general move towards universal religions, showing how the success of global religions can be related to their ability to meet the desire of modernity of many Guineans, and to connect the believers with the rest of the world.

KEYWORDS: religion, evangelical Christianity, Guinea-Bissau, post-colonial state, modernity, mobility.

FORMENTI, Ambra (ambra.formenti@gmail.com) - Centro em Rede de Investigação em Antropologia, Faculdade de Ciências Sociais e Humanas, Universidade Nova de Lisboa (CRIA-FCSH/NOVA), Portugal. 


\section{LIMPANDO A PORTA DA NAÇÃO}

No final de 2012, um grupo de mulheres evangélicas organizou uma limpeza ritual no aeroporto de Bissau: primeiro elas oraram; em seguida lavaram o local com baldes e vassouras; finalmente pregaram aos viajantes e funcionários. ${ }^{1}$ Conforme explicou a líder da associação, o objetivo desta iniciativa era "alcançar as almas" dos que lá trabalhavam, assim como orar por qualquer pessoa que viesse com "más ideias", "más intenções" e "maus hábitos". Segundo me foi dito, esta ação foi um desafio e uma tarefa crucial, porque o aeroporto, tal como qualquer chave ou fronteira, é "a porta de entrada de todas as coisas". Podem entrar boas ideias, mas também podem entrar "ideias e materiais negativos", tais como a droga, que costuma entrar no país por esta via.

Este acontecimento destaca uma das questões centrais que têm marcado a história do movimento evangélico na Guiné-Bissau: a dialética entre abertura e encerramento, conexão e desconexão. Porta de entrada para o país, ponto de possíveis ligações globais, lugar de trânsito de objetos, ideias e pessoas, símbolo das relações que ligam os guineenses ao resto do planeta, o aeroporto representa riscos e oportunidades inerentes à abertura ao mundo. Ao mesmo tempo, este episódio traz à tona muitas características da cena evangélica contemporânea: a sua recente projeção para a arena pública, o seu impulso moralizador em relação à sociedade, a sua capacidade de criar e gerir redes transnacionais.

O presente artigo pretende dar uma contribuição para o estudo da religião na África Ocidental, focando o caso ainda pouco investigado do protestantismo na Guiné-Bissau, um país onde as confissões cristãs têm sido tradicionalmente minoritárias, em comparação com o Islão e as religiões locais. A partir de uma perspetiva histórico-antropológica, nas páginas seguintes vou descrever a trajetória da minoria evangélica guineense desde a chegada dos primeiros missionários até ao presente, tendo como pano de fundo o processo de descolonização e a história pós-independência do país. Este texto baseia-se num trabalho de campo realizado em Bissau no início de 2013, com o objetivo de reconstruir uma genealogia do movimento evangélico na Guiné-Bissau, na ausência de uma literatura exaustiva sobre o assunto. ${ }^{2}$ Graças à participação e ao interesse da comunidade evangélica local, realizei 22 entrevistas em

l Os movimentos evangélicos são as correntes de renovação espiritual que têm origem na Reforma protestante, incluindo o pietismo, o metodismo, algumas correntes batistas e o pentecostalismo. Por vezes, o termo "evangélico" é usado para distinguir o protestantismo histórico dos movimentos mais recentes; outras vezes, é usado como sinónimo de "protestante". Neste artigo uso as duas palavras alternadamente, dado que as correntes mais antigas do protestantismo tiveram um papel secundário na trajetória do movimento evangélico guineense.

2 Na literatura académica sobre religião na Guiné-Bissau, são ainda poucos os textos que abordaram o tema da presença evangélica, à exceção dos trabalhos de José Júlio Gonçalves (1960) e Eduardo Costa Dias (1999). Já no que diz respeito às fontes primárias, destacam-se os livros da missionária Hazel Wallis (1996) e do pastor Ernesto Lima (2007). 
profundidade e histórias de vida com pastores, missionários, líderes e crentes cristãos. Juntamente com a análise de relatórios, publicações e outros documentos produzidos por organizações evangélicas, a gravação de cultos e a observação participante em várias atividades religiosas, este material etnográfico constitui o fundamento da presente contribuição. A prevalência das fontes orais no meu trabalho deve-se à destruição parcial de arquivos públicos e privados, na sequência da guerra civil que devastou Bissau entre 1998 e 1999. Como já foi observado por vários autores, a especificidade dos documentos orais reside na sua capacidade de dar voz à memória coletiva, entendida como o conjunto dos processos de seleção, remoção e interpretação através dos quais determinados grupos e comunidades representam o passado em função do presente (Halbwachs 1950, 1976; Fabietti e Matera 1999). Se, por um lado, as fontes orais permitem dar um lugar central aos atores que viveram a história na primeira pessoa, trazendo à luz os significados que os entrevistados atribuem ao passado coletivo, por outro lado, elas não podem ser consideradas objetivas, devido à sua natureza intrinsecamente artificial, variável e parcial (Portelli 1998). O mesmo se pode dizer da literatura primária utilizada na presente contribuição, nomeadamente aquela produzida por membros influentes da Igreja Evangélica da Guiné-Bissau, a principal e mais antiga organização protestante guineense (Brierley 1955; Wallis 1996; Lima 2007), menos preocupada com a "verdade" factual dos eventos passados do que com a eficácia retórico-pedagógica da mensagem transmitida.

Com base neste material etnográfico, na primeira parte do artigo ilustrarei as origens e as transformações do movimento evangélico guineense ao longo do tempo. Longe de apresentar uma panorâmica completa e imparcial, este artigo oferece uma primeira abordagem de um assunto pouco explorado por historiadores e cientistas sociais. Dando voz aos protagonistas deste percurso, o presente trabalho abre o caminho para investigações futuras, que cruzem entre si fontes orais com fontes escritas, multiplicando os pontos de vista para fornecer um quadro mais detalhado e complexo. Na segunda parte do texto focar-me-ei na descrição do contexto contemporâneo, examinando o crescimento do cristianismo protestante no âmbito de uma viragem geral para as religiões universais, tanto nas zonas urbanas, como nas áreas rurais do país. Para interpretar as transformações mais recentes do movimento evangélico guineense, vou propor duas possíveis linhas de análise, uma baseada na cena histórico-política local e outra relacionada com os processos globais.

\section{HISTÓRIA DO MOVIMENTO EVANGÉLICO NA GUINÉ-BISSAU, 1940-2013}

Apesar da pequena dimensão da sua população, que é de cerca um milhão e meio de habitantes, a Guiné-Bissau é caracterizada por um grande pluralismo religioso, resultante de uma série de fluxos migratórios e rotas comerciais que 
cruzaram o seu território ao longo dos séculos (Rodney 1970; Brooks 1993, 2003; Knörr e Trajano Filho 2010). Como ilustraram Ramon Sarró e Miguel de Barros (2016), a região tem sido ao longo do tempo o cenário de um encontro entre três fronteiras religiosas. A primeira é a fronteira interna africana (Kopytoff 1987), ou seja, a ocupação da terra através da segmentação e expansão de grupos de agricultores e pastores, acompanhada por noções de contratos espirituais entre os espíritos (irãs, em crioulo), donos do lugar, e os primeiros ocupantes humanos. A segunda é a fronteira muçulmana, que se expandiu de leste para oeste desde o século XIII. Entre as sucessivas vagas de clérigos, comerciantes e guerreiros muçulmanos que atravessaram a região, particularmente importantes foram os impérios de Gabu, que se tornou proeminente na região no século XVI, e Futa Jallon, que anexou o reino de Gabu no século XIX. Os descendentes desses impérios, respetivamente mandingas e fulas, ainda contestam o controle da cena muçulmana na atual Guiné-Bissau. Tradicionalmente, a fronteira muçulmana tem sido localizada na zona leste do país, sem atingir a costa ocidental. A última é a fronteira católica-atlântica, constituída pela sociedade cristã crioula que surgiu nos centros costeiros de Farim, Geba, Bolama e Cacheu a partir do século XVI. A expansão católica avançou ao longo das redes comerciais e sociais que existiam entre os navegadores portugueses, cabo-verdianos e luso-africanos, que controlavam o tráfico de escravos, e os grupos do interior (Brooks 2003; Trajano Filho 1993, 2010). Neste território, o catolicismo foi institucionalmente estabelecido em 1533, com a criação da diocese de Cabo Verde e Guiné (Rema 1982; Pélissier 1997; Djaló 2012). Contudo, até recentemente, a sua influência ficou limitada aos centros crioulos ao longo da costa e, mais tarde, à área de Bissau, enquanto o seu sucesso nas áreas rurais foi muito reduzido até recentemente (Sarró e Barros 2016).

Neste ecossistema religioso, o cristianismo evangélico tem sido ultraminoritário até aos anos 1990 (Dias 1999). Em comparação com a presença católica, a história da minoria protestante é muito recente, tendo a sua génese nos meados do século XX. De acordo com a história oral e a literatura primária, a origem do movimento evangélico na Guiné remonta a 20 de maio de 1940, quando a jovem missionária britânica Bessie Fricker zarpou da cidade da Praia, em Cabo Verde, para Bolama, antiga capital da então colónia portuguesa (Wallis 1996; Lima 2007). O ano de 1940 foi crucial para a política religiosa do Estado Novo: com a assinatura da Concordata com o Vaticano e do Acordo Missionário, o governo comprometeu-se a apoiar o trabalho religioso e social das missões católicas nos territórios ultramarinos, limitando a instalação de missões não católicas. Em troca, a Santa Sé aceitou que a maioria das autoridades eclesiásticas nas colónias africanas fosse de nacionalidade portuguesa. Na Guiné Portuguesa, estas disposições contribuíram para promover o papel social da Igreja Católica, especialmente nos domínios da saúde e da educação, como se tornou evidente na atribuição exclusiva do chamado "ensino indígena" às missões 
católicas, em 1941 (Koudawo 2001). Devido a essas circunstâncias e a um contexto geopolítico marcado pela concorrência entre potências europeias para o controlo do continente africano, as origens da minoria evangélica na Guiné foram marcadas pela hostilidade das autoridades portuguesas para com os missionários protestantes, que eram, na sua maioria, de nacionalidade estrangeira.

Com base na história oral e na literatura primária, é possível reconhecer três fases na trajetória do movimento evangélico guineense: os primórdios (de 1940 a 1974); a institucionalização (de 1974 a 1998); a expansão (de 1998 até hoje).

\section{Primórdios}

Bessie Fricker pertencia à Worldwide Evangelization Crusade (a seguir designada WEC), uma agência missionária internacional com sede no Reino Unido. ${ }^{3}$ Em 1946 Bessie, juntamente com o marido Leslie Brierley (também membro da WEC), estabeleceu-se em Bissau, para onde a capital da colónia tinha sido recentemente transferida. Depois de um período de negociação com a administração colonial, a WEC foi autorizada a conduzir atividades missionárias sob o nome de Missão Evangélica (a seguir designada ME). Até à independência, em 1974, esta foi a única organização protestante oficialmente reconhecida pelas autoridades. De acordo com os meus entrevistados e com as fontes primárias, os primeiros missionários vieram principalmente de Inglaterra, dos Estados Unidos e, em menor número, da Alemanha.

Durante esta longa fase inicial, a ação missionária focou-se nos grandes centros populacionais, principalmente na capital, onde nasceu o primeiro núcleo do protestantismo guineense. Em consequência, o alvo principal da evangelização protestante foram as camadas urbanas e crioulas. Como a pregação em locais públicos era proibida pelas autoridades, o primeiro grupo de oração reunia-se em casas particulares, no centro da cidade. Uma vez que os sermões foram inicialmente dados em língua portuguesa, os primeiros convertidos pertenciam à classe mais alta e escolarizada, que do ponto de vista jurídico se enquadrava na categoria de "assimilado" ${ }^{4}$ incluindo tanto a minoria

3 A organização foi criada em 1913 pelo missionário britânico Charles Thomas Studd, de formação anglicana, mas influenciado pelas doutrinas metodistas e da santificação (holiness), que insistiam na necessidade de que cada cristão atingisse a perfeição moral, através de uma conduta ascética e moralmente irrepreensível. No entanto, a WEC era uma organização interdenominacional: para pertencer à agência, cada membro tinha que deixar de lado a sua própria filiação original. Inicialmente chamada Heart of Africa Mission, o seu nome foi alterado para Worldwide Evangelization Crusade em 1919, sendo finalmente mudado para Worldwide Evangelization for Christ Internacional em 1982 (Davies 2012).

4 O princípio de assimilação tinha o seu fundamento no Estatuto dos Indígenas (promulgado em 1926, revisto em 1954 e abolido em 1961), que consagrava juridicamente o sistema de relações profundamente desiguais entre colonizados e colonizadores que existia nas colónias africanas [continua] 
cabo-verdiana como o grupo dos luso-guineenses. ${ }^{5}$ Este núcleo primitivo criou a Igreja Central, a primeira congregação evangélica no país. Mais tarde, outras congregações de língua crioula surgiram nos subúrbios, agregando novos fiéis que pertenciam às classes mais baixas e analfabetas. Esta distribuição espacial da estratificação social manteve-se como uma característica distinta do movimento até ao presente, sendo um reflexo da complexidade da sociedade crioula guineense, que inclui tanto as elites luso-guineenses, residentes no centro da cidade, como os grupos vindos das zonas rurais, que tendem a instalar-se nos arredores (Trajano Filho 2010). Em 1974 havia cinco congregações em Bissau: Igreja Central, Igreja de Belém, Igreja de Bandim, Igreja de Antula e Igreja de Missira.

Além da região de Bissau, pequenas igrejas foram implantadas nas áreas de Bolama, Bissorã, Empada, Catió, Biombo, e nas ilhas Bijagós. Em 1950, uma clínica destinada à cura da lepra foi estabelecida em Bissorã (sendo mais tarde transferida para a aldeia vizinha de Lendene), sob a direção do médico evangélico norte-americano Herbert Billman (Billman 1951; Gonçalves 1960; Dias 1999). Em 1962, um centro materno-infantil foi inaugurado em Biombo, com o apoio da UNICEF e do Ministério da Saúde português (Lima 2007). Nas áreas rurais, os novos convertidos pertenciam aos grupos étnicos balanta, papel e bijagó, que ocupavam as regiões atingidas pela incipiente ação missionária da ME. Um dos pilares da ação missionária evangélica entre os grupos indígenas foi a tradução da Bíblia para as línguas locais. O resultado deste trabalho, que começou na década de 1950, foi a publicação do Novo Testamento nas línguas bijagó (em 1989), papel (em 1994) e balanta (em 2012), e da Bíblia em crioulo (em 1998). Em 1970, a ME fundou a primeira denominação protestante no país, a Igreja Evangélica da Província da Guiné, mais tarde renomeada

[continuação] portuguesas. Com base nesta legislação, os habitantes da Guiné, de Angola e de Moçambique eram formalmente divididos em "civilizados" e "indígenas": enquanto a primeira categoria incluía os cidadãos europeus, sujeitos à lei portuguesa, a segunda compreendia a grande maioria da população, excluída da organização jurídica portuguesa, privada de direitos civis, sujeita a coerções específicas e governada pelo direito consuetudinário local (Alexandre 2005). Em 1954, o Estatuto foi sujeito a uma revisão assimilacionista, incluindo na categoria dos "civilizados" uma estrita minoria de "assimilados" formada por luso-descendentes e cidadãos de origem cabo-verdiana, que exerciam funções administrativas e eram legalmente equiparados aos cidadãos portugueses. A fim de obter o estatuto de "assimilado", os nativos deviam respeitar um conjunto de requisitos, incluindo falar e escrever em língua portuguesa, ser cristãos, ter um emprego remunerado e renunciar aos usos e costumes do próprio grupo de origem. De acordo com Tcherno Djaló (2012), estes critérios socioeconómicos e culturais eram tais que, na véspera da guerra colonial, apenas $0,4 \%$ da população guineense era abrangida por este regime.

5 Em literatura, o termo "luso-africanos" (Brooks 1993, 2003; Trajano Filho 2010) é utilizado para designar as pessoas de ascendência mista, africana e portuguesa, que nasceram nos centros costeiros dedicados ao tráfico atlântico na África Ocidental. Por "luso-guineenses" Tcherno Djaló (2012) entende a camada superior da sociedade crioula guineense, composta por comerciantes, pequenos funcionários, empregados da administração colonial e indivíduos pertencentes às profissões liberais. 
Igreja Evangélica da Guiné-Bissau (a seguir designada IEGB). No entanto, neste período a comunidade evangélica cresceu muito lentamente, chegando a cerca de mil crentes logo após a independência, segundo fontes da IEGB.

De acordo com muitas testemunhas, um dos fatores que limitou a expansão do movimento nesta fase inicial foi a guerra colonial (1963-1974). Segundo uma narrativa recorrente, a concentração das atividades missionárias nos arredores de Bissau seria atribuível às drásticas limitações impostas pelo governo português à mobilidade da população durante a guerra, especialmente entre a capital e as zonas de conflito no interior do país. De acordo com a maioria dos entrevistados, a ME como instituição não teve qualquer envolvimento na guerra colonial. A neutralidade dos missionários protestantes na luta pela independência da Guiné estaria em contraste com o que aconteceu em Moçambique e em Angola, onde as igrejas Presbiteriana, Metodista e Congregacional desempenharam um papel central na formação das elites nacionalistas que lideraram a luta anticolonial (Silva 2001, 2004; Schubert 1999; Ngoenha 1999; Paredes 2010). No caso da Guiné Portuguesa, a atitude apolítica dos missionários protestantes desencorajou a participação dos crentes evangélicos no conflito. No entanto, alguns crentes desempenharam papéis determinantes na guerra de libertação, como foi o caso de Rafael Barbosa, um dos líderes fundadores do PAIGC, ${ }^{6}$ que operava clandestinamente na área de Bissau, mobilizando jovens para a guerrilha. ${ }^{7}$ Consequentemente, apesar da posição de distanciamento declarada pelos missionários, a real ou suposta simpatia da comunidade evangélica pela frente de libertação provocou a reação repressiva do governo colonial, que culminou em 1963 com a execução de alguns crentes evangélicos pela PIDE, a polícia política portuguesa. Conforme relatado por Ernesto Lima (2007), naquele ano o evangelista Formoso Mendes foi torturado e executado na prisão de Cantchungo, o seu cadáver arrastado por um carro e mostrado aos habitantes da aldeia; o ancião Dinis Gomes Barbosa foi assassinado e queimado na sua casa por um comando português em Cubisseco; os líderes da Igreja de Empada, Victor Vaz Martins e Pedro Silva, foram torturados e brutalmente assassinados em Empada, juntamente com outros membros da congregação local. Para além destes massacres, as autoridades fecharam a clínica evangélica de Lendene, acusando a equipa médica de ajudar a guerrilha.

Os meus interlocutores discordaram sobre a amplitude do envolvimento de crentes evangélicos no conflito colonial. De acordo com o pastor Joaquim Correia, estes episódios de repressão seriam imputáveis à desconfiança das autoridades coloniais para com o trabalho missionário no interior do país:

6 O Partido Africano da Independência da Guiné e Cabo Verde (PAIGC), dirigido por Amílcar Cabral, foi o movimento que liderou a luta de libertação na Guiné Portuguesa e em Cabo Verde, tornando-se o principal partido político na Guiné-Bissau independente.

7 O próprio Luís Cabral, irmão de Amílcar e primeiro presidente da República da Guiné-Bissau, pertenceu à Igreja do Nazareno na sua juventude (Cabral 2015). 
"Muitas vezes os evangelistas iam [nas áreas rurais] com um trabalho de evangelização, mas como também o PAIGC na altura fazia o mesmo tipo de coisas para a mobilização de gente para a luta armada, então os portugueses não sabiam distinguir entre o evangelista e o próprio soldado. Então algumas vezes os evangelistas foram presos e mortos".

Pelo contrário, segundo Helena Barbosa, filha de Rafael Barbosa, os evangélicos tiveram um papel crucial na guerra de libertação:

"Quando uma pessoa acredita em Deus, acredita na Bíblia, acredita na Palavra de Deus, há certas posições que não consegue tomar. Já é diferente. Portanto mobilizaram muita gente. Porque, afinal de contas, a luta surgiu como? Ninguém gosta da injustiça [...]. Foi por isso que toda a gente aderiu à luta de libertação. Portanto a Igreja Evangélica teve um papel extraordinário, quando mostrou que ninguém pode fazer aquilo que Deus não permite. Mesmo lutando, mesmo indo para frente, já tem outro comportamento".

Tratando-se de um assunto controverso, o tema do envolvimento evangélico na guerra colonial precisa de mais investigação, cruzando fontes orais e escritas. No entanto, independentemente da participação de crentes protestantes no conflito, tanto a literatura como os entrevistados concordam em descrever a comunidade evangélica como um grupo marginal e pouco ativo na cena sociopolítica até à instauração da República.

\section{Institucionalização}

Os meus interlocutores destacaram vários fatores que contribuíram para o crescimento gradual da minoria evangélica na Guiné-Bissau libertada. Em primeiro lugar, após a independência tornou-se mais fácil viajar por todo o país, o que promoveu progressivamente a evangelização das zonas rurais. Em segundo lugar, na década de 1980 a IEGB iniciou um processo de emancipação da ME, graças ao desenvolvimento de uma liderança nacional. Aos poucos, as bases locais da Igreja tornaram-se mais fortes e organizadas. Em 1978, Ernesto Lima foi o primeiro guineense a assumir o cargo de presidente do Conselho Nacional, o órgão máximo da IEGB. Em 1990, os missionários estrangeiros deixaram de ter qualquer responsabilidade na direção, e a Igreja tornou-se financeiramente independente. Em 1991, a IEGB foi a primeira denominação oficialmente reconhecida pelo governo.

Em terceiro lugar, a Constituição da República declarou formalmente a liberdade religiosa num Estado secular. Como explicou o pastor José Paulo Semedo, o evento que mais marcou esta fase foi o processo de liberalização económica e política, desencadeado pela adoção, em 1986, de um programa de ajustamento estrutural. Nesta altura, o presidente Nino Vieira, que tinha 
chegado ao poder com um golpe de Estado em 1980, foi forçado pela crise económica a pedir um resgate financeiro junto do Fundo Monetário Internacional e do Banco Mundial. Em troca de ajudas, as organizações internacionais exigiram uma série de medidas económicas e políticas e reajustes constitucionais, incluindo a transição para o sistema multipartidário e o reconhecimento dos direitos de cidadania fundamentais, entre os quais a liberdade religiosa (Barros 2012). Embora a Constituição de 1973 salvaguardasse formalmente o direito de praticar qualquer religião, as organizações religiosas não eram legalmente reconhecidas. Em contrapartida, a nova versão da Constituição regulava de maneira mais clara as relações entre Estado e instituições religiosas, autorizando a liberdade de culto, o direito de ensino de qualquer religião e a proteção das confissões reconhecidas legalmente. Um dos efeitos desse processo foi a multiplicação de lugares de culto e denominações evangélicas, tanto de origem nacional como estrangeira. Se até àquele momento a ME e a IEGB tinham sido as únicas organizações protestantes presentes no país, a partir da década de 1990 novas denominações internacionais foram autorizadas a estabelecer congregações no território nacional, incluindo igrejas vindas do Brasil, dos Estados Unidos, da Nigéria e do Gana. Depois da IEGB, as primeiras organizações cristãs a serem legalizadas foram a Jovens com Uma Missão (Jocum), as Assembleias de Deus, a Igreja Filadélfia, a Igreja Vida Profunda, a Igreja Ide e a Ministério de Amor pela Fé Internacional. As últimas a estabelecerem-se foram as denominações de matriz neopentecostal, como a Igreja Universal do Reino de Deus (IURD), a Deus é Amor, a Igreja Redimida, a Capela dos Vencedores e a Capela do Farol.

Foi também nesta década que tanto a IEGB como as igrejas mais novas começaram a criar ligações transnacionais com organizações evangélicas fora do país, principalmente no Brasil, o que favoreceu a circulação transnacional dos crentes. Por um lado, um número crescente de missionários brasileiros foram cumprindo obra espiritual, social e sanitária na Guiné. Por outro lado, uma geração de líderes evangélicos começou a sair da Guiné-Bissau para obter uma formação teológica no estrangeiro, especialmente no Brasil, mas também em outros países africanos, no Reino Unido e em Portugal. De forma mais geral, a criação de redes religiosas transnacionais favoreceu a mobilidade global dos jovens crentes, principalmente através da atribuição de bolsas de estudo internacionais.

\section{Expansão}

Esta abertura para o exterior foi interrompida pela eclosão da guerra civil em 1998. ${ }^{8}$ Apesar de ter produzido uma pausa temporária na ampliação da 
minoria evangélica, o conflito fomentou o crescimento do movimento nos anos seguintes de várias maneiras. Muitos dos meus interlocutores realçaram como a concentração das hostilidades na área de Bissau provocou um êxodo da capital, empurrando os fiéis para o interior do país e favorecendo a evangelização das áreas rurais. Outras testemunhas sublinharam como, durante a guerra, a liderança protestante adquiriu um papel público crucial. Por um lado, a IEGB, através do seu representante, o pastor Ernesto Lima, participou nos trabalhos da Comissão de Mediação da Boa Vontade, uma equipa formada por atores da sociedade civil e dirigida pelo bispo católico Settimio Arturo Ferrazzetta, com vista à reconciliação entre as partes em conflito (Lima 2007). Por outro lado, durante toda a duração das hostilidades, as igrejas evangélicas contribuíram para a distribuição de ajudas internacionais junto da população, em colaboração com a Igreja Católica e algumas ONG.

Apesar de permanecer uma minoria, na última década o movimento evangélico tem sido capaz de capitalizar o papel público que ganhou durante a guerra civil, aumentando o número dos seus membros e tornando-se cada vez mais visível no espaço público. ${ }^{9}$ Ao mesmo tempo, em consonância com o caráter separatista do cristianismo protestante, este rápido crescimento resultou na multiplicação das divisões e na diferenciação interna do movimento, que hoje inclui tanto as correntes conservadoras como as igrejas de inspiração pentecostal. A fim de criar uma forma de unidade, representar a comunidade evangélica junto às autoridades, coordenar as suas ações e estabelecer ligações com associações evangélicas de outros países, em 2000 um grupo de igrejas fundou a Aliança Evangélica Guineense (AEG). ${ }^{10}$

Nas narrativas dos seus protagonistas, o movimento evangélico na Guiné-Bissau é representado como uma comunidade que, em 70 anos, evoluiu de uma minoria marginal para uma força crescente no país, capaz de competir com o Islão e o catolicismo na batalha pelo monopólio das almas dos guineenses. Apesar de constituir uma descrição subjetiva e parcial, esta representação parece ser confirmada pelos dados estatísticos mais recentes e pela observação da presença evangélica, tanto no espaço urbano como nos meios de comunicação na Guiné-Bissau contemporânea. Analisando estas

9 Para uma discussão da categoria de espaço público, ver nota 13.

10 Os membros fundadores da AEG foram a IEGB, as Assembleias de Deus, a WEC, a Igreja Kairós, a Junta de Missões Mundiais (Igreja Batista), a Igreja Filadélfia, a Vida Profunda e a Jocum. Enquanto outras denominações se juntaram à Aliança nos anos seguintes, igrejas de inspiração neopentecostal, como a IURD e a Deus é Amor, ficaram excluídas, por serem consideradas demasiado distantes dos princípios evangélicos e por propagarem a controversa doutrina da prosperidade, que considera a riqueza material e o bem-estar como bênçãos de Deus e sinais de graça divina (Corten e Marshall-Fratani 2001; Marshall 2009). 
narrativas à luz da recente literatura sobre Estado pós-colonial, ${ }^{11}$ religião, modernidade e globalização na Guiné-Bissau e na África Ocidental, na próxima secção exploro algumas pistas de reflexão sobre os múltiplos fatores que influenciaram esta trajetória ascendente, delineando duas possíveis linhas de interpretação.

\section{A MINORIA EVANGÉLICA, DA SEPARAÇÃO À PARTICIPAÇÃO}

De acordo com o primeiro Recenseamento Geral da População, em 1979 cerca de $35 \%$ da população guineense era muçulmana, $60 \%$ praticava as religiões indígenas e 5\% era cristã (Machado 2002). O censo de 2009 (INE 2009) mostrou um surpreendente crescimento do cristianismo (22\%), um aumento do Islão (45\%) e um declínio das religiões locais (15\%). Se estes dados devem ser interpretados com cuidado (pois $16 \%$ da população não respondeu à pergunta sobre a religião praticada), a ascensão do cristianismo, o progresso contínuo do Islão e a descida das religiões indígenas são evidentes. Apesar da ausência de números mais detalhados, de acordo com os líderes religiosos entrevistados, tanto a Igreja Católica como o bloco protestante estariam experimentando uma forte expansão em todo o país.

O incremento do cristianismo evangélico é ainda mais notável quando confrontado com a exiguidade da minoria protestante antes da independência. José Júlio Gonçalves (1960) apontou como, em 1950, os protestantes formavam uma comunidade estatisticamente insignificante, com $2,2 \%$ entre os "civilizados" e 0,008\% entre os "não civilizados", chegando a um total de 820 fiéis em 1957. No que diz respeito à IEGB, de acordo com o pastor Caetano Indami, presidente do Conselho Nacional em 2013, o número total dos mem-

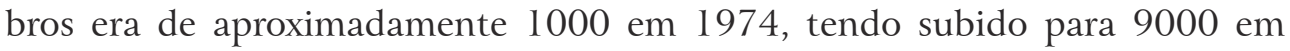
1990, 12.000 em 2000, 30.000-40.000 em 2012.

Se o recente avanço do cristianismo evangélico na paisagem religiosa guineense pode ser dado por certo, como poderá ser interpretado? Nas páginas seguintes vou tentar delinear algumas possíveis respostas.

11 O termo "pós-colonial” tem gerado um intenso debate. De acordo com os seus críticos, a ideia de "consequencialidade" associada ao sufixo "pós" ocultaria a permanência de relações coloniais no atual contexto de capitalismo global, apesar de a maioria das antigas colónias ter alcançado a independência formal (McClintock 1992; Loomba 2005). Como sugerido por Robert Young (2001), muitos dos problemas levantados podem ser resolvidos se o "pós-colonial" for definido como posterior ao colonialismo, no seu significado original de dominação direta, sem implicar o fim do imperialismo, no seu sentido de sistema global de desigualdade económica. Numa aceção mais específica, as ciências políticas e sociais usaram a expressão "Estado pós-colonial" com referência às novas nações que nasceram das lutas anticoloniais, como a Guiné-Bissau (Forrest 2003; Chabal et al. 2002; Chabal e Green 2016). É com esta última conotação que uso o conceito de "pós-colonial” no presente artigo. 


\section{Redimindo o Estado pós-colonial}

Cheguei a Bissau em 31 de dezembro de 2012. Em 12 de abril do mesmo ano, um golpe de Estado tinha derrubado o governo democraticamente eleito, instalando uma administração transitória. Longe de ser uma novidade, as mudanças de poder pela força e os conflitos entre chefias políticas e militares têm sido uma constante desde a independência. Na era pós-colonial, a Guiné-Bissau sofreu três golpes (em 1980, 2003 e 2012) e uma guerra civil (1998-99), além de várias tentativas de tomar o poder pela força, seguidas de assassinatos políticos e violações de direitos humanos. Além disso, a partir da década de 2000 o país transformou-se gradualmente num ponto de trânsito para os narcóticos que viajam da América do Sul para a Europa, com o envolvimento de representantes da política e do exército no tráfico internacional de droga. A instabilidade política, a incapacidade do Estado para implementar políticas sociais e económicas a nível regional, a dependência económica do apoio externo, a crescente corrupção e as conexões entre classe política, exército e redes criminosas transnacionais levaram vários observadores a caracterizar a República da Guiné-Bissau como um Estado "frágil" (Forrest 2003; Barros 2013) ou um "narco-Estado" (Horta 2007; Walt 2007; Vulliamy 2008). ${ }^{12}$

No entanto, como apontaram Chabal e Green (2016), estes eventos parecem ter pouco impacto na sociedade guineense, para além da classe política. Aparentemente, a vida quotidiana no país permanece pacífica, sendo marcada pela ausência de conflitos interétnicos ou religiosos, pela autonomia das comunidades rurais e pela omnipresença da economia informal. De acordo com alguns autores, o Estado tornou-se "irrelevante" para muitos guineenses (Bordonaro 2009a). Apesar da instabilidade no cenário político, na minha estadia em Bissau no início de 2013 não tive a perceção de um clima de tensão no dia-a-dia. Em vez disso, o que me chamou a atenção foi a ausência do Estado na vida das pessoas. Na capital respirava-se um clima de incerteza e suspensão, devido à frequente interrupção do funcionamento das escolas e à paralisação da burocracia. A distribuição de água e eletricidade era descontínua, as estradas estavam muito danificadas, e os serviços sociais, incluindo a saúde e a escola pública, eram insuficientes. As pessoas descreviam as estruturas estatais como deficientes e julgavam que a maioria dos funcionários civis e militares estariam envolvidos em negócios ilícitos e apropriação de recursos públicos. Todos viam a Guiné-Bissau como um país saqueado e abandonado pelos seus governantes corruptos. Contudo, a reação mais comum a esta situação era uma forma de resignação crítica. Uma frase recorrente nas conversas era "djitu ka tem": não há nada a fazer, temos de aceitar as coisas como elas são, porque não há nenhuma maneira de mudá-las (Bordonaro 2009b).

12 Para uma discussão destas categorias e uma análise atualizada da crise do Estado pós-colonial na Guiné-Bissau, ver Chabal e Green (2016). 
Enquanto o Estado guineense parece recuar, cada vez mais, do campo social e da economia formal, interrompendo o fornecimento dos serviços sociais mais básicos, uma série de outros atores estão a emergir no espaço público fora da esfera estatal, incluindo ONG, organizações internacionais, redes de tráfico de droga e autoridades locais no meio rural. ${ }^{13}$ Neste conjunto de atores, que concorrem para a criação de uma "nova e instável economia do poder" e para uma profunda "redefinição da esfera política" (Bordonaro 2009a: 38), um papel crucial é desempenhado pelas instituições religiosas, tanto islâmicas como cristãs. Tal como aconteceu em outros países da África Ocidental, a proliferação de movimentos religiosos resultou na criação de espaços não estatais, capazes de produzir formas alternativas de solidariedade e previdência social. Com efeito, as organizações religiosas muçulmanas e cristãs tornam-se cada vez mais ativas na provisão de recursos de saúde, educação e infraestruturas básicas, especialmente nas áreas rurais, onde as estruturas estatais são mais deficientes (Koudawo 2001; Gaillard 2002). Embora não tenham como objetivo a subversão do Estado, estas redes religiosas demonstram a incompletude da intervenção governativa sobre a sociedade (Marshall 2009; Piot 2010).

13 Por "espaço público", ou "esfera pública”, José Casanova (1994) entendeu uma dimensão constitutiva das três arenas que constituem o sistema governamental moderno: o Estado, a sociedade política e a sociedade civil. Tomando como ponto de partida o papel mais proeminente da religião na cena mundial desde os anos 1980, o autor argumenta que estamos a assistir a uma "desprivatização" da religião no mundo moderno. Isto entra em contradição com as teorias da secularização, segundo as quais as religiões estariam destinadas, nas sociedades modernas, a um declínio progressivo e a um recuo para a esfera privada. Contudo, de acordo com Casanova, só as religiões públicas que abandonaram as suas aspirações a serem instituições integradas no Estado, focando a sua atividade ao nível da sociedade civil, seriam "consistentes com os princípios universalistas modernos e com as estruturas diferenciadas da modernidade" (Casanova 1994: 219). Como foi enfatizado por vários autores (Knoblauch et al. 2011 ), o texto de Casanova forneceu aos cientistas sociais um vocabulário conceptual para discutir o papel da religião na sociedade além do paradigma da secularização. No entanto, outros observadores argumentaram que a ideia de desprivatização não fornece uma ferramenta analítica adequada para a compreensão da dinâmica religiosa em África, uma vez que a religião nunca deixou de desempenhar um papel político nas sociedades africanas. Como foi observado por Gerrie ter Haar (2008), nas cosmologias indígenas africanas tanto a religião como a política são consideradas modos de pensar, organizar e conquistar o poder. Por contraste, as instituições formais de governo que foram criadas na época colonial correspondiam a ideias europeias sobre a separação da política e da religião no governo do Estado-nação, uma visão que foi continuada pela primeira geração de nacionalistas africanos. Porém, desde o fim da Guerra Fria em 1989, fomos assistindo a uma nova projeção da religião no espaço público, à medida que as ideologias nacionalistas perdiam credibilidade e as pessoas procuravam novas fontes de legitimidade e poder, incluindo os próprios políticos (Ter Haar 2008: 34). Criticando tanto o "ateísmo prescritivo" dos Estados africanos de partido único como o extremismo teocrático do Islão radical, Lamin Sanneh (2015 [1996]) alegou que o papel público da religião na África contemporânea consiste na sua função de árbitro moral. Na visão do autor, a separação entre Estado e instituições religiosas não implica necessariamente a exclusão da religião do espaço público, nem a desconexão entre ética e política, "piedade e poder". Pelo contrário, é na convergência entre liberalismo democrático, liberdade religiosa e pluralismo religioso que pode ter lugar o encontro inter-religioso na esfera pública africana contemporânea. 
Como sugeriram Ramon Sarró e Miguel de Barros (2016), a guerra de 1998-99 foi um ponto de viragem na história religiosa do país. Foi a partir desse momento que as organizações religiosas se envolveram mais ativamente no campo sociopolítico, como se tornou evidente pelo seu papel de mediadores e agentes humanitários durante o conflito e na reconstrução da paisagem política nos anos seguintes. Enquanto as instituições religiosas eram vistas com desconfiança pelos primeiros governos independentes, hoje em dia as religiões estão presentes, cada vez mais, no espaço público. Em Bissau, mesquitas e igrejas pentecostais estão especialmente empenhadas em captar a atenção dos cidadãos, por meio de grafitos, cartazes publicitários, altifalantes e campanhas de conversão. Também os canais da rádio e da televisão são usados pelas organizações religiosas como poderosos meios de proselitismo, enquanto os líderes muçulmanos e cristãos aparecem frequentemente em noticiários e programas de opinião na TV nacional. ${ }^{14}$

Num primeiro nível de análise, a expansão da minoria evangélica nas últimas décadas pode ser interpretada como uma resposta à crise do Estado guineense, permanentemente sujeito à instabilidade política, corrupção e falência financeira, num estado de "instabilidade permanente" (Vigh 2010) desde a independência. Neste sentido, o recente crescimento do movimento pode ser representado como a evolução de uma comunidade relativamente segregada, com foco na separação do mundo, para um movimento aberto, que opera ativamente no espaço público, tanto na esfera religiosa como no campo sociopolítico.

A marginalidade da comunidade originária estava ligada a vários fatores. Por um lado, os primeiros missionários protestantes foram isolados e discriminados pela administração portuguesa, devido à sua origem estrangeira e à rivalidade com a Igreja Católica. Por outro lado, a sua formação moralmente conservadora, próxima das correntes metodistas e holiness, predispunha-os a um foco no retiro espiritual, numa rígida conduta moral e numa vida inspirada no ascetismo e na perfeição cristã. $\mathrm{Na}$ opinião deles, a fim de se libertar do pecado, o crente devia praticar uma rotura não só com os rituais ancestrais, mas também com os riscos de corrupção inerentes à vida política e ao poder temporal. Pelo contrário, nos últimos anos o foco dominante tem sido a atividade social e a participação na vida pública. Como salienta Elizabeth Fernandes, líder de um grupo de jovens cristãos, hoje os evangélicos "querem sair da igreja para fazerem a diferença no mundo, para serem a luz no mundo". Elizabeth, tal como outros entrevistados, atribui esta viragem intramundana à emergência de uma liderança nacional que substituiu a antiga direção dos

14 Entre os meios de comunicação social ligados a organizações evangélicas e pentecostais, realça-se a Rádio Luz, fundada pelo pastor brasileiro Cláudio Silva, das Assembleias de Deus, e a Record TV, que pertence à IURD e transmite da sua sede no Brasil. 
missionários estrangeiros e se mostrou mais inclinada para o envolvimento na vida sociopolítica do país.

Hoje em dia, em contraste com um Estado percebido como cada vez mais ausente, a minoria evangélica guineense parece praticar uma dupla estratégia de intervenção social e política: verifica-se, por um lado, a tentativa de colmatar as lacunas do Estado através da ação social; por outro, um programa de "redenção do Estado" através da conversão dos atores políticos. Em primeiro lugar, as igrejas estão envolvidas na construção de redes sociais relativamente independentes, que proporcionam aos seus membros serviços sociais e laços de solidariedade. Embora a construção e administração de clínicas e escolas tenha sido um elemento central das missões protestantes desde o início da sua presença no país, o envolvimento social evangélico intensificou-se no princípio da década de 2000. Foi nesta altura que a IEGB criou a Central Social, um organismo especificamente dedicado à ação social, cujo objetivo, como afirmou o seu diretor pastor José Paulo Semedo, é "a construção de uma escola em cada lugar onde está a ser implantada uma igreja”. No entanto, o trabalho social não se limita à IEGB: pelo contrário, muitas outras denominações nacionais e internacionais estão atualmente a implementar projetos comunitários em todo o país. ${ }^{15}$ Uma vez que são potencialmente dirigidos à população em geral, estes recursos constituem um potente meio de proselitismo, ajudando os agentes religiosos a expandir a sua audiência. Ao nível das narrativas, muitos dos meus interlocutores descreveram as igrejas evangélicas como tendo o "monopólio da esperança" na Guiné-Bissau, em contraste com o desespero da maioria das pessoas, vítimas de fome e doenças e abandonadas pelo Estado. Nas palavras do pastor Dionísio Rodrigues, missionário da IEGB na província Leste:

"Muitos políticos não andam onde eu ando, eu tenho informações que eles não têm [...]. Nós vamos até às tabancas [aldeias] das fronteiras, onde não tem um posto médico, não tem educação, não tem nada. $O$ povo, para ter ideia, não sente a presença do Estado ali naqueles lugares [...]. Mas a Igreja está lá. No pouco recurso que a Igreja tem, a Igreja tenta suprir aquelas necessidades básicas da população, o que o Estado não faz [...]. No tempo da chuva, praticamente é tempo de fome nas tabancas. Você vê crianças com fome $[\ldots]$, as grávidas morrem muito. E chega o tempo das eleições, dão um saco de arroz para cada pessoa... ficam contentes e vão votar, e no outro dia continuam a morrer! Muito desespero no meio do povo. Mas eu creio que isso é uma época que estamos a viver na Guiné, vai passar tudo isto. A Guiné

15 Em Bissau, um dos projetos mais conhecidos é a Casa Emanuel, um centro multifuncional fundado pela médica e missionária Isabel Johanning Mora, natural da Costa Rica. O centro inclui uma clínica médica, uma escola básica, um liceu, uma escola profissional e um lar para crianças abandonadas (ver $<$ http://www.casaemanuel.org > última consulta em junho de 2017). 
vai se aflorar, vamos ter bons dias [...], vamos encontrar pessoas que amam esta terra, que amam este país, e que se interessam por ele realmente, que lutam [para] que este país se estabilize [...]. É muito triste a nossa situação, mas como sempre dizem, a esperança é a última que morre, então nós temos a esperança na Guiné-Bissau”.

Apesar da sua componente autocelebrativa, estes discursos relatam uma realidade concreta, ou seja, a combinação entre serviços religiosos e sociais na estratégia missionária das igrejas evangélicas e, mais em geral, dos movimentos religiosos, na Guiné-Bissau contemporânea.

Em segundo lugar, alguns setores do movimento evangélico estão a desempenhar um papel cada vez mais ativo na política nacional. Em princípio, as igrejas evangélicas afirmam a separação entre fé e política. Enquanto cada crente é livre de tomar parte na vida política como cidadão, as instituições religiosas evitam posicionamentos oficiais sobre assuntos políticos, deixando liberdade de consciência aos seus membros. Foi precisamente devido a esta neutralidade que os líderes da IEGB puderam desempenhar um papel de intercessão em conflitos militares e políticos nos anos passados, como no caso do pastor Ernesto Lima, que pertenceu à equipa de mediação durante a guerra civil de 1998-99 (Lima 2007). Além disso, nos últimos anos, algumas figuras ilustres da comunidade evangélica desempenharam funções públicas relevantes. É o caso do pastor Joaquim Correia, assessor para assuntos religiosos do Presidente da República de transição em 2012-13, Manuel Serifo Nhamadjo. Entre as igrejas protestantes, a IEGB continua a desempenhar um papel de destaque no relacionamento com as autoridades, principalmente através de Conselho Nacional e da Igreja Central, uma congregação que tem sido tradicionalmente vocacionada para a evangelização da elite guineense. Desta forma, ao longo dos anos, o núcleo originário luso-guineense da comunidade protestante tem assegurado um canal de mediação entre as redes evangélicas e a classe dirigente.

A integração de elementos evangélicos no aparelho estatal parece responder à lógica da assimilação das elites africanas descrita por Jean-François Bayart (1989): através da captação de líderes evangélicos, a elite no poder parece perseguir o duplo objetivo de ganhar o eleitorado cristão e controlar, ao mesmo tempo, as fontes de potencial dissidência. Este processo assumiu maior visibilidade nas últimas décadas, à medida que a cena política guineense se foi tornando mais marcada por referências a identidades étnicas e religiosas. Como apontaram vários observadores, desde meados da década de 1990, a transição para um sistema multipartidário tem levado a classe política a tirar partido das clivagens étnicas e religiosas, a fim de ganhar partes do eleitorado, enquanto os discursos socialistas e nacionalistas foram perdendo popularidade (Fernandes 1993; Carvalho 2000; Gaillard 2002; Silva 2010). 
No entanto, do ponto de vista da comunidade evangélica, a entrada na cena política parece adquirir um significado diferente, uma vez que a política pode ser vista como um instrumento para cristianizar e redimir a nação. $\mathrm{Na}$ opinião de muitos crentes, que interpretam o atual estado das coisas na Guiné-Bissau como uma grave crise moral, a única forma eficaz para moralizar o Estado seria a conversão dos seus representantes. Esta é a firme convicção do pastor Félix da Costa, empenhado no trabalho missionário entre as forças armadas:

"Quando uma pessoa tem contacto com a Palavra de Deus, esta pessoa é transformada. Então eu comecei a pensar: com certeza, os militares aqui na Guiné-Bissau, se eles tiverem contacto com o Evangelho, eles podem ser transformados. Aí comecei a ir aos quartéis [...]. É um trabalho que vale a pena, eu acredito que se houver mais abertura para a pregação do Evangelho nos quartéis vai mudar muita coisa. Porque eu acredito que um homem que conhece Deus é um homem diferente. Na sua maneira de agir, é um homem que pondera antes de agir, antes de fazer alguma coisa, esse homem lembra Deus, lembra que tem que prestar contas daquilo que ele vai fazer, então ali vem o temor do seu Deus [...]. Porque aqui as pessoas temem muito os militares. Os militares, em outras palavras, estão acima da lei. Mas o homem que teme a Deus sabe que pode estar acima da lei dos homens, mas tem a lei de Deus que está acima de todos: queira ou não queira, você está debaixo da lei de Deus e vai prestar contas, como a Bíblia disse".

As palavras do pastor Félix revelam um projeto de redenção individual e coletivo largamente partilhado entre os crentes evangélicos guineenses: um programa totalizador em que a conversão individual abre o espaço para a salvação política da nação. Na medida em que "um homem que conhece Deus é um homem diferente", tanto na esfera espiritual como na conduta com outras pessoas, a conversão torna-se um meio para criar o "cidadão ideal" (Marshall 2009). Longe de querer uma revolução ou uma mudança radical do sistema político atual, o programa político evangélico aponta para a redenção da sociedade e do Estado através da conversão dos indivíduos. Esta, de acordo com muitos crentes, seria a única maneira para pôr fim ao ciclo de violência, corrupção e pobreza que afeta a Guiné-Bissau desde a independência. Sendo percebida como uma resposta a um sentido generalizado de crise moral, a agenda política evangélica configura-se como um esforço para criar uma "comunidade moral" (Karlström 2004) cristã, baseada na solidariedade social, na observância da lei de Deus e, como veremos, nas ideias de desenvolvimento e modernidade. Apesar da sua divergência em relação aos projetos políticos mais convencionais, esta "política antipolítica" (Piot 2010), baseada menos na agência coletiva 
do que na mudança individual e na intervenção divina, teria na perspetiva evangélica um forte potencial transformador do mundo. Contudo, na medida em que funciona através da filiação religiosa, este programa tende a promover obrigações e compromissos exclusivos, em vez de inclusivos. De facto, ao estigmatizar tanto as religiões locais como o Islão, este programa exclui idealmente o "outro" religioso num país caracterizado por uma grande pluralidade confessional, revelando uma dificuldade em criar as bases para uma comunidade política inclusiva e exprimindo, nas palavras da Ruth Marshall (2009), uma "teologia política negativa".

\section{Rumo a uma fé global}

Num segundo nível de análise, o crescimento do cristianismo evangélico pode ser interpretado no contexto de uma mudança geral para as religiões universais, que está recentemente a envolver tanto as populações rurais como as camadas urbanas na Guiné-Bissau contemporânea. Como já referido, a década de 1990 foi um momento crucial na história religiosa guineense. O impacto do processo de liberalização económica e política no estabelecimento de denominações evangélicas internacionais no território nacional foi ilustrado nas páginas anteriores. Como foi observado por Gérald Gaillard (2002), a mesma dinâmica ocorreu em âmbito islâmico: a maioria das grandes mesquitas de Bissau foram construídas entre 1986 e 1991, com recursos da Arábia Saudita, do Koweit e da Líbia, e no mesmo período começaram a proliferar as escolas corânicas e as associações islâmicas de solidariedade social. Segundo o autor, estas organizações estão fortemente comprometidas com a conversão de grupos tradicionalmente dedicados às religiões indígenas, e com a propagação de um Islão reformista entre as comunidades que praticam o Islão tradicional africano. Em oposição às confrarias muçulmanas locais, jovens missionários treinados no estrangeiro estariam a promover uma forma de Islão inspirada no rigor interpretativo do Alcorão (Gaillard 2002).

Por um lado, a expansão do Islão e do cristianismo no interior do país está em conformidade com tendências de longo prazo. Enquanto no passado os clérigos muçulmanos eram raramente ativos nos centros cristãos e o proselitismo cristão nas áreas muçulmanas era escasso e pouco bem-sucedido (Dias 1999), as zonas intersticiais, como a área de Oio ao longo do rio Geba, habitada por agricultores balanta, eram consideradas, pelos agentes de ambas as religiões, reservatórios para novos convertidos (Sarró e Barros 2016). Por outro lado, o recente sucesso das confissões universais entre grupos étnicos tradicionalmente dedicados às religiões indígenas, como os balanta, parece ter atingido uma dimensão sem precedentes. Nos últimos anos, os meios de comunicação social têm noticiado conversões em massa de inteiras comunidades, como no caso da área de Nhoma, no setor de Nhacra, onde em janeiro de 2013 cerca de 5000 agricultores balanta se teriam convertido ao 
Islão. ${ }^{16}$ As organizações evangélicas - especialmente as de inspiração pentecostal vindas do Brasil - são também muito ativas entre as comunidades balanta, concentrando-se menos nas conversões coletivas do que nas individuais. Finalmente, uma estratégia similar é seguida pela Igreja Católica: a ordenação, em 2000, do primeiro bispo de origens balanta, monsenhor José Camnaté, faz sentido à luz desta corrida para a conversão das assim chamadas populações "animistas".

O crescimento do cristianismo e do Islão é significativo num contexto em que, especialmente entre as camadas mais jovens e urbanizadas, as práticas rituais tradicionais são associadas, cada vez mais, aos poderes ocultos e ao subdesenvolvimento, enquanto as religiões universais são relacionadas com uma forma "moderna" de vida (Gable 1995; Bordonaro 2009b, 20 10). ${ }^{17}$ Como apontou Lorenzo Bordonaro (2009b), a noção de modernidade é traduzida em crioulo pelo conceito de "desenvolvimento", uma palavra-chave tanto da retórica nacional pós-independência como do discurso da cooperação internacional. Conforme ilustrado pelo autor, este termo é reformulado e apropriado pelos jovens urbanizados das ilhas Bijagós como uma ferramenta retórica para contestar as autoridades tradicionais das aldeias, num contexto marcado por uma tensão geracional de longa data. Ao mesmo tempo, a aspiração à vida moderna seria o resultado de uma autoperceção comum entre os jovens que vivem nas cidades guineenses, marcada por um sentimento de marginalidade, exclusão e imobilidade social, num contexto caracterizado pelo contraste entre uma disponibilidade de imagens e bens estrangeiros, por um lado, e uma falta de oportunidades para os mais novos, por outro. Nestas circunstâncias, a migração para Europa e Brasil é vista como uma das poucas vias para reivindicar uma cidadania na modernidade, reivindicação expressa na frase recorrente em crioulo "sai fora", "ir embora" (Bordonaro 2009b).

Se, por um lado, as populações rurais são estigmatizadas pelos habitantes das cidades como representantes de um modo de vida e de uma visão do mundo tradicional, que seria um obstáculo ao progresso e à modernização do

16 Apesar do impacto mediático destas notícias, não podemos esquecer que, como salientam vários observadores (Trajano Filho 2010; Sarró e Barros 2016), a conversão das religiões indígenas para as religiões universais na Guiné-Bissau tem sido historicamente marcada por ambiguidades e negociações. De facto, tanto o catolicismo como o Islão guineense têm sido caracterizados por formas de sincretismo e dualismo religioso, que incluem, por exemplo, a participação ocasional dos fiéis em rituais tradicionais. Apesar de ser fortemente estigmatizado, o recurso às práticas religiosas locais não deixa de acontecer até nas confissões mais radicais, tais como as igrejas evangélicas e o Islão reformista.

17 Para uma análise detalhada da noção de modernidade, veja-se, entre outros, Miller (1994), Appadurai (1996, 2013), Knauft (2002), Ferguson (2006), Bordonaro e Carvalho (2010). Neste artigo, uso este termo não como uma categoria analítica, mas como "língua local" (Ferguson 1999) e uma "ideologia de aspiração" (Knauft 2002) que surgiu no atual contexto de um mundo interconectado, mas de forma seletiva e descontínua. 
país, por outro lado, as religiões indígenas são desacreditadas pelos líderes das confissões universais, que alegam a existência de uma relação estreita entre a feitiçaria e as práticas religiosas locais. Nestas circunstâncias, no meio rural a conversão ao Islão e ao cristianismo pode afigurar-se como uma reação face à representação das comunidades das aldeias como "primitivas", "supersticiosas" e "tradicionais". Assim, como argumentaram Ramon Sarró e Miguel de Barros (2016), o sucesso do Islão e do pentecostalismo no interior do país pode ser interpretado como "um mecanismo local para alcançar a modernidade e para conectar-se ao resto do mundo" (Sarró e Barros 2016: 1 19). Esta hipótese faz sentido se assumirmos, de acordo com James Ferguson, que em África a modernidade é vista principalmente como um "status social que implica certas condições institucionais e económicas de vida" (Ferguson 2006: 168), e que o desejo de modernidade expressa uma "reivindicação de iguais direitos de participação numa sociedade global espetacularmente desigual" (Ferguson 2006: 175). Na medida em que "ser moderno" significa "ser conectado" ao resto do mundo, no meio rural a conversão às religiões universais pode ser entendida como uma maneira de ter acesso, material ou simbolicamente, ao desenvolvimento, ao bem-estar e à melhoria das condições de vida através das redes religiosas.

Longe de estar limitada ao caso guineense, a relação entre cristianismo evangélico e projeções de modernidade foi observada em vários contextos africanos (Van Dijk 1997; Meyer 1999, 2004; Táíwò 2010; Macamo 2005). Se a maioria destes autores concordam em atribuir um lugar central ao tema da modernidade no discurso evangélico africano, os seus trabalhos mostraram como diferentes igrejas oferecem respostas diferenciadas às tentativas locais de enfrentar e interpretar as mudanças sociais, conceptuais e económicas trazidas pela globalização. Por exemplo, Birgit Meyer (1999) interpretou a centralidade das imagens de Satanás nas apropriações locais do pentecostalismo entre os ewe do Gana como um meio pelo qual os crentes enfrentam os aspetos atraentes, preocupantes e destrutivos do seu encontro com a economia, a política e a cultura global. Pelo contrário, como sugeriu Rijk van Dijk (1997), o sucesso do pentecostalismo urbano entre os jovens de classe média no Gana e em outros países africanos pode ser atribuído à sua capacidade de proporcionar uma rede de ligações transnacionais, e de usar os modernos meios de comunicação para propagar as suas mensagens, focadas no sucesso pessoal e na prosperidade como sinais da graça divina.

No caso do cristianismo evangélico guineense, as igrejas correspondem às aspirações à modernidade dos seus membros de várias maneiras. Em primeiro lugar, elas ligam idealmente os crentes com a comunidade global em Cristo. Muitos autores têm apontado as orientações explicitamente globais dos movimentos cristãos contemporâneos (Coleman 2000; Knibbe 2009). A tendência para afirmar uma identidade baseada na ideia de um cristianismo universal, independente de conotações nacionais ou étnicas, foi observada em vários 
contextos, como revela a recorrência do termo "internacional" nos nomes de muitas igrejas, especialmente no meio pentecostal (Van Dijk 1997; Ter Haar 1998; Schiller, Çaglar e Guldbrandsen 2006). A mesma vocação universalista é evidente em muitas denominações presentes na Guiné-Bissau, tais como a Ministério de Amor pela Fé Internacional e a Junta de Missões Mundiais. Assim, graças à inserção numa irmandade global, as igrejas evangélicas e pentecostais permitem aos seus membros imaginarem-se como parte de um mundo mais amplo. Em segundo lugar, para além de ligar os crentes com uma comunidade imaginada transnacional, as congregações evangélicas proporcionam-lhes também recursos mais tangíveis. Na verdade, na medida em que as redes religiosas constituem uma forma de capital social, em muitos casos a filiação evangélica acaba por constituir um trampolim ou uma rede de segurança para projetos de mobilidade. De facto, através das redes das igrejas, muitos crentes conseguem obter documentos de viagem, tais como vistos médicos, de estudo e de turismo, que, devido às restrições legais, à corrupção e à ineficiência burocrática, são inacessíveis para a maioria da população guineense. Em terceiro lugar, as igrejas promovem roturas com os padrões tradicionais de género e geração e com as obrigações de parentesco. Por exemplo, conforme referido pelos meus entrevistados, as igrejas costumam fornecer abrigo e suporte às jovens mulheres que fogem do assim chamado "casamento forçado". ${ }^{18}$ Talvez não seja por acaso que o cristianismo evangélico tem uma audiência privilegiada entre os jovens e as mulheres, que encontram nas igrejas um espaço para contestar a hegemonia dos homens mais velhos, para escolher os seus próprios parceiros e para expressar "novos idiomas de amor, autonomia individual e família nuclear” (Sarró e Barros 2016: 121). Finalmente, as conexões evangélicas proporcionam recursos de identidade e laços sociais para os crentes que conseguem sair do país, facilitando a sua navegação através dos espaços transnacionais e melhorando as suas condições de vida nos lugares de destino (Van Dijk 1997; Formenti 2014).

\section{CONCLUSÃO}

Ao longo da sua trajetória histórica, o movimento evangélico guineense sofreu mudanças importantes, evoluindo de uma pequena comunidade religiosa, relativamente segregada, socialmente marginal e com foco na separação do mundo, para uma minoria numericamente significativa que vai rapidamente

18 Como observaram Sílvia Roque e a sua equipa (Roque 201 1), na Guiné-Bissau o casamento arranjado, ou seja, a escolha do cônjuge por parte dos pais ou de outros familiares, é uma prática comum, que não é encarada necessariamente como violência. No entanto, o uso do termo "casamento forçado" é cada vez mais frequente, à medida que crescem os casos de recusa das meninas e mulheres jovens em relação a esta prática. 
ganhando poder e visibilidade no espaço público, tanto na esfera religiosa como no campo sociopolítico.

A década de 1990 foi um período crucial na história do movimento: desde então, as conversões começaram a crescer mais rapidamente do que nos anos anteriores, para o que contribuiu a chegada de novas denominações internacionais. O maior ponto de viragem na trajetória protestante foi, provavelmente, a guerra civil de 1998-99, devido ao papel fundamental desempenhado pelas igrejas evangélicas no processo de mediação e nas iniciativas humanitárias durante o conflito.

Esta evolução tem de ser colocada no quadro mais geral do sucesso ascendente das religiões universais entre a população guineense, em contraste com o aparente declínio das religióes locais. Por um lado, o crescimento do Islão, do catolicismo e do protestantismo pode ser atribuído ao ativismo social das organizações religiosas, enquanto o Estado está a retirar-se cada vez mais do campo social. Por outro lado, o sucesso das religióes globais pode ser relacionado com a sua capacidade de promoverem a ligação dos fiéis com o mundo através de redes transnacionais, num contexto onde cada jovem guineense quer "ir embora".

A referência à dimensão global do movimento evangélico guineense permite-me retornar ao episódio que abre este artigo. A crescente relevância das igrejas evangélicas na arena social e política guineense parece estar associada à sua capacidade de implementar estratégias de extroversão. Neste sentido, a realização de uma limpeza ritual no aeroporto, espaço de fronteira emblemático, parece ser especialmente reveladora da aspiração evangélica a gerir o trânsito de objetos, ideias e pessoas entre a Guiné-Bissau e o resto do mundo. Ao expressar a sua vontade de decidir "o que pode entrar" e "o que não pode entrar" no espaço nacional, as mulheres evangélicas afirmaram a sua determinação em redimir a nação. O lado obscuro deste impulso moralizador é a estigmatização do "outro" religioso, numa visão do mundo maniqueísta em que tanto o tráfico de droga, a corrupção e a violência política, como as cosmologias e as cerimónias locais são associadas aos poderes ocultos e atribuídas à ação de Satanás.

A capacidade de exercer formas de controlo sobre a circulação transnacional e de estabelecer ligações globais criadoras de oportunidades parece ser assim, hoje em dia, um marco distintivo do movimento evangélico guineense. Em contraste com um Estado-nação que se mostra cada vez mais incapaz de responder ao desejo de modernidade da maioria da população, o sucesso das igrejas evangélicas parece residir nas suas promessas de transformação pessoal, melhoria da qualidade de vida e ligação ao mundo. 


\section{BIBLIOGRAFIA}

ALEXANDRE, Valentim, 2005, “O Império colonial”, em António Costa Pinto (org.), Portugal Contemporâneo. Lisboa, Dom Quixote, 67-86.

APPADURAI, Arjun, 1996, Modernity at Large: Cultural Dimensions of Globalization. Minneapolis, University of Minnesota Press.

APPADURAI, Arjun, 2013, The Future as Cultural Fact: Essays on the Global Condition. Londres, Verso Books.

BARroS, Miguel José de, 2012, "A sociedade civil face ao processo de democratização e o desenvolvimento na Guiné-Bissau (1991-2011)", Africana Studia, 18: 37-47.

BARROS, Miguel José de, 2013, “Les conséquences du narcotrafic sur un Etat fragile: le cas de la Guinée-Bissau", Alternatives Sud, 20: 145-158.

BAYART, Jean-François, 1989, L'Etat en Afrique: la politique du ventre. Paris, Fayard.

BILLMAN, Herbert, 1951, "Primeiro relatório anual dos trabalhos da Missão Evangélica no tratamento da lepra na província da Guiné Portuguesa", Boletim Cultural da Guiné Portuguesa, VI (23): 697-702.

BORDONARO, Lorenzo, 2009a, "Introduction: Guinea-Bissau today: the irrelevance of the State and the permanence of change", African Studies Review, 52 (2): 35-45.

BORDONARO, Lorenzo, 2009b, "Sai fora: youth, disconnectedness and aspiration to mobility in the Bijagó Islands (Guinea-Bissau)”, Etnográfica, 13 (1): 125-144.

BORDONARO, Lorenzo, 2010, "Modernity as marginality: the making and the experience of peripherality in the Bijagó Islands (Guinea-Bissau)", Cadernos de Estudos Africanos, 18-19: 117-137.

BORDONARO, Lorenzo, e Clara CARVALHO, 2010, "Introduction”, Cadernos de Estudos Africanos, 18-19: 9-18.

BRIERLEY, Leslie, 1955, “A obra evangélica na Guiné Portuguesa”, Portugal d’Aquém e d'Além Mar, 19 (73): 63-64.

BROOKS, George E., 1993, Landlords and Strangers: Ecology, Society, and Trade in Western Africa, 1000-1630. Boulder, CO, Westview Press.

BROOKS, George E., 2003, Eurafricans in Western Africa: Commerce, Social Status, Gender, and Religious Observance from the Sixteenth to the Eighteenth Century. Oxford, James Currey Publishers.

CABRAL, Luís, 2015, Memórias e Discursos. Lisboa, Fundação Amílcar Cabral.

CARVALHO, Clara, 2000, "A revitalização do poder tradicional e os regulados mandjaco da Guiné-Bissau", Etnográfica, IV (1): 37-59.

CASANOVA, José, 1994, Public Religions in the Modern World. Chicago, The University of Chicago Press.

CHABAL, Patrick, e Toby GReEN, 2016, Guinea-Bissau: Micro-State to "Narco-State”. Londres, Hurst \& Co.

CHABAL, Patrick, et al., 2002, A History of Postcolonial Lusophone Africa. Londres, C. Hurst \& Co. Publishers.

COLEMAN, Simon, 2000, The Globalisation of Charismatic Christianity: Spreading the Gospel of Prosperity. Cambridge, Cambridge University Press.

CORTEN, Andre, e Ruth R. MARSHALL-FRATANI, 2001, Between Babel and Pentecost: Transnational Pentecostalism in Africa and Latin America. Bloomington, IN, Indiana University Press. 
DAVIES, Evan, 2012, Whatever Happened to CT Studd's Mission? Lessons from the History of WEC International. Bulstrode, WEC Publications.

DIAS, Eduardo Costa, 1999, "Protestantismo e proselitismo na Guiné-Bissau: reflexões sobre o insucesso do proselitismo no Oio e na província Leste", Lusotopie, 1999: 309$-318$.

DJALÓ, Tcherno, 2012, O Mestiço e o Poder: Identidades, Dominações e Resistências na Guiné. Lisboa, Vega.

FABIETTI, Ugo, e Vincenzo MATERA, 1999, Memoria e Identità: Simboli e Strategie del Ricordo. Roma, Meltemi.

FERGUSON, James, 1999, Expectations of Modernity: Myths and Meanings of Urban Life on the Zambian Copperbelt. Berkeley, University of California Press.

FERGUSON, James, 2006, Global Shadows: Africa in the Neoliberal World Order. Durham, NC, Duke University Press.

FERNANDES, Raúl Mendes Jr., 1993, "Partido único e poderes tradicionais”, Soronda, 16: 39-50.

FORMENTI, Ambra, 2014, Going for God: Mobility, Place and Temporality among Evangelical Guineans in Lisbon. Lisboa, Instituto de Ciências Sociais da Universidade de Lisboa, tese de doutoramento.

FORREST, Joshua, 2003, Lineages of State Fragility: Rural Civil Society in Guinea-Bissau. Athens, $\mathrm{OH}$, Ohio University Press.

GABLE, Eric, 1995, "The decolonization of consciousness: local skeptics and the "will to be modern' in a West African village”, American Ethnologist, 22 (2): 242-257.

GAILLARD, Gérald, 2002, "Islam et vie politique en Guiné-Bissau contemporaine", em Islams d'Afrique: entre le local et le global. Paris, Karthala, 191-209 (col. L'Afrique politique).

GONÇALVeS, José Júlio, 1960, Protestantismo em África: Contribuição para o Estudo do Protestantismo na África Portuguesa. Lisboa, Junta de Investigações de Ultramar.

HALBWACHS, Maurice, 1950, La mémoire collective: Ouvrage posthume publié. Paris, Presses Universitaires de France.

HALBWACHS, Maurice, 1976, Les cadres sociaux de la mémoire. Nova Iorque, Walter de Gruyter.

HORTA, Loro, 2007, “Guinea Bissau: Africa’s first narcostate”, African Studies Center, University of Pennsylvania, disponível em < http://www.africa.upenn.edu/Articles_Gen/gui nbisauhorta.html > (última consulta em junho de 2017).

INE, 2009, Terceiro Recenseamento Geral da População e Habitação: Características Socioculturais.

Bissau, Instituto Nacional de Estatística, disponível em < http://www.stat-guinebissau.c om/publicacao/caracteristicas_socio_cultural.pdf > (última consulta em junho de 2017).

KARLSTRÖM, Mikael, 2004, "Modernity and its aspirants: moral community and developmental Eutopianism in Buganda", Current Anthropology, 45 (5): 595-619.

KNAUFT, Bruce M. (org.), 2002, Critically Modern: Alternatives, Alterities, Anthropologies. Bloomington, IN, Indiana University Press.

KNIBBE, Kim, 2009, “'We did not come here as tenants, but as landlords': Nigerian Pentecostals and the power of maps", African Diaspora, 2 (2): 133-158.

KNOBLAUCH, et al., 2011 , "Portrait: José Casanova", Religion and Society, 2 (1): 5-36.

KNÖRR, Jacqueline, e Wilson TRAJANO FILHO (orgs.), 2010, The Powerful Presence of the Past: Integration and Conflict along the Upper Guinea Coast. Leiden, Brill. 
KOPYTOFF, Igor, 1987, The African Frontier: The Reproduction of Traditional African Societies. Bloomington, IN, Indiana University Press.

KOUDAWO, Fafali, 2001, Cabo Verde e Guiné Bissau: Da Democracia Revolucionária à Democracia Liberal. Bissau, Instituto Nacional de Estudo e Pesquisa.

LIMA, Ernesto, 2007, O Evangelho de Cristo na Guiné-Bissau: Dos Primórdios aos Nossos Dias. Lisboa, Publidisa.

LOOMBA, Ania, 2005, Colonialism/Postcolonialism. Londres e Nova Iorque, Routledge (2. ${ }^{\mathrm{a}}$ edição).

MACAMO, Elisio Salvado, 2005, Negotiating Modernity: Africa’s Ambivalent Experience. Dakar, CODESRIA.

MACHADO, Fernando Luís, 2002, Contrastes e Continuidades: Migração, Etnicidade e Integração dos Guineenses em Portugal. Oeiras, Celta Editora.

MARShall, Ruth, 2009, Political Spiritualities: The Pentecostal Revolution in Nigeria. Chicago, The University of Chicago Press.

McCLINTOCK, Anne, 1992, “The angel of progress: pitfalls of the term 'post-colonialism' ", Social Text, 3 1-32: 84-98.

MEYER, Birgit, 1999, Translating the Devil: Religion and Modernity among the Ewe in Ghana. Edimburgo, Edinburgh University Press.

MEYER, Birgit, 2004, "Christianity in Africa: from African independent to Pentecostal-Charismatic churches”, Annual Review of Anthropology, 33 (1): 447-474.

MILlER, Daniel, 1994, Modernity, an Ethnographic Approach. Oxford, Berg Publishers.

NGOENHA, Severino Elias, 1999, "Os missionários suíços face ao nacionalismo moçambicano: entre a tsonganidade e a moçambicanidade”, Lusotopie, 1999: 425-436.

PAREDES, Margarida, 2010, "Deolinda Rodrigues: da família metodista à família MPLA, o papel da cultura na política", Cadernos de Estudos Africanos, 20: 11-26.

PÉLISSIER, René, 1997, História da Guiné: Portugueses e Africanos na Senegâmbia, 1841-1936. Lisboa, Editorial Estampa.

PIOT, Charles, 2010, Nostalgia for the Future: West Africa after the Cold War. Chicago, The University of Chicago Press.

PORTELLI, Alessandro, 1998, "What makes oral history different", em Robert Perks e Alistair Thomson (orgs.), The Oral History Reader. Londres e Nova Iorque, Routledge.

REMA, Henrique Pinto, 1982, História das Missões Católicas da Guiné. Braga, Editorial Franciscana.

RODNEY, Walter, 1970, A History of the Upper Guinea Coast, 1541-1800. Oxford, Clarendon Press.

ROQUE, Sílvia (org.), 201 1, Um Retrato da Violência contra Mulheres na Guiné-Bissau. Bissau, Governo da República da Guiné-Bissau e Nações Unidas.

SANNEH, Lamin, 2015 [1996], Piety and Power: Muslims and Christians in West Africa. Eugene, OR, Wipf and Stock.

SARRÓ, Ramon, e Miguel de BARROS, 2016, "History, mixture modernity", em Patrick Chabal e Toby Green (orgs.), Guinea-Bissau: Micro-State to Narco-State. Londres, Hurst Publishers.

SCHILlER, Nina Glick, Ayşe ÇAGLAR, e Thaddeus C. GULDBRANDSEN, 2006, "Beyond the ethnic lens: locality, globality, and born-again incorporation”, American Ethnologist, 33 (4): 612-633.

SCHUBERT, B., 1999, "Os protestantes na guerra angolana depois da independência”, Lusotopie, 1999: 595-596. 
SILVA, António Duarte, 2010, Invenção e Construção da Guiné-Bissau: Administração Colonial/Nacionalismo/Constitucionalismo. Coimbra, Edições Almedina.

SILVA, Teresa Cruz e, 2001, Protestant Churches and the Formation of Political Consciousness in Southern Mozambique (1930-1974). Basileia, P. Schlettwein Publishing.

SILVA, Teresa Cruz e, 2004, "Identidade religiosa e construção da democracia em Moçambique: o caso da Igreja Metodista Unida de Moçambique”, Travessias, 4-5: 223-235.

TÁíWÒ, Olúfémi, 2010, How Colonialism Preempted Modernity in Africa. Bloomington, IN, Indiana University Press.

TER HAAR, Gerrie, 1998, Halfway to Paradise: African Christians in Europe. Cardiff, Cardiff Academic Press.

TER HAAR, Gerrie, 2008, "Enchantment and identity: African Christians in Europe", Archive des Sciences Sociales des Religions, 143: 31-48.

TRAJANO FILHO, Wilson, 1993, Rumores: Uma Narrativa da Nação. Brasília, Departamento de Antropologia da Universidade de Brasília (Série Antropologia, n. ${ }^{\circ}$ 143).

TRAJANO FILHO, Wilson, 2010, "The Creole idea of nation and its predicaments: the case of Guinea-Bissau", em Jacqueline Knörr e Wilson Trajano Filho (orgs.), The Powerful Presence of the Past: Integration and Conflict along the Upper Guinean Coast. Leiden, Brill, 157-184.

VAN DIJK, Rijk, 1997, "From camp to encompassment: discourses of transsubjectivity in the Ghanaian Pentecostal diaspora”, Journal of Religion in Africa, 27: 135-159.

VIGH, Henrik, 2010, "Youth mobilisation as social navigation: reflections on the concept of dubriagem”, Cadernos de Estudos Africanos, 18-19: 140-164.

VULLIAMY, Ed, 2008, "How a tiny West African country became the world's first narco state, The Guardian, 9 de março.

WALlIS, Hazel, 1996, Luz Numia na Sukuru: Storia di Igreza Ivangeliku di Gine-Bissau, 1949-1974. Bubaque, Missão Evangélica.

WALT, Vivienne, 2007, "Cocaine country", Time, 27 de junho.

YOUNG, Robert, 200 1, Postcolonialism: An Historical Introduction. Oxford, UK, e Malden, MA, Wiley-Blackwell. 